\title{
Procesos de Agenciamiento Junto A Stop Represión GranAdA Y UN EJERCICIO DE AUTOETNOGRAFÍA VULNERABLE
}

\section{Processes of agencement together with Stop Repression Granada and $a$ vulnerable autoethnography exercise}

\author{
Ariana S. Cota \\ IUEMG, Universidad de Granada (España)
}

\section{Palabras clave}

Agenciamiento colectivo

Resistencia

Etnografía

feminista

Vulnerabilidad

\section{Keywords}

Collective agencement

Resistance

Feminist

Ethnography

Vulnerability
RESUMEN: En este artículo, propongo comprender los procesos de agenciamiento de Stop Represión Granada, grupo al que pertenezco, como resistencia al poder y como construcción de proyecto propio. Apoyándome en la propuesta de la antropóloga Sherry Ortner, empleo una noción de agencia que no remite a un actor individual, sino a los grupos que cuestionan la dominación en sus contextos, desvelan sus contradicciones y aspiran a un cambio social. Para comprender nuestro grupo como un proceso de agenciamiento, analizo dos experiencias colectivas: la resistencia al poder - la lucha contra las "Listas Negras»-, y la construcción de proyecto propio -el "seminario Feminismos»-. Emplear el método autoetnográfico me ha permitido profundizar no sólo en la relación entre vulnerabilidad y agenciamientos colectivos, sino igualmente en mi condición vulnerable como investigadora académica que estudia un grupo al que pertenece. A partir del análisis de nuestra experiencia propongo que ambas nociones - vulnerabilidad y agencia- se encuentran más que se distancian. Así, el objetivo no ha de ser superar las vulnerabilidades, sino de asumirlas en plenitud, como un modo de «estar juntas» y «hacer cosas juntas».

ABSTRACT: In this paper I propose to understand agencement processes within Stop Repression Granada, a collective group I belong to, as a resistance to power and as a construction of a project of one's own. Using anthropologist Sherry Ortner's proposal, I develop a notion of agency that does not refer to an individual actor, but to groups that question domination within their contexts, disclose their contradictions and aspire to a social change. In order to understand our group as an agencement process, I analyze two collective experiences: one on resistance to power - the struggle against «Black Lists»-, and another on the construction of a project of one's own - the «Feminisms Seminar»- The autoethnography method employed has allowed me to delve not only into the relationship between vulnerability and collective agencements, but equally into my vulnerable condition as an academic researcher who studies a group she belongs to. From the analysis of our own experience I propose that both notions - vulnerability and agency - converge more than they diverge. Therefore, the aim should not be to overcome vulnerabilities but to accept them completely, as a way to «be together» and "do things together».

Correspondencia a / Correspondence to: Ariana S. Cota. Instituto Universitario de Estudios de las Mujeres y del Género (IUEMG). Universidad de Granada. Calle Rector López Argueta, s/n. 18071 Granada. - ariana@correo.ugr.es - http://orcid.org/0000-0001-5332-6846.

Cómo citar / How to cite: Cota, Ariana S. (2019). «Procesos de agenciamiento junto a Stop Represión Granada y un ejercicio de autoetnografía vulnerable»; Papeles del CEIC, vol. 2019/1, papel 207, 1-19. (http://dx.doi.org/10.1387/pceic.19530).

Recibido: marzo, 2018; aceptado: noviembre, 2018.

ISSN 1695-6494 / ㄷ 2019 UPV/EHU 
A lo largo de estos años, se han escrito numerosos artículos y monografías en torno al ciclo de protesta que inició el «Movimiento de l@s indignad@s 15M» en 2011, pero mucho menos sobre el ciclo de represión que el Estado español acompasó desde ese momento y que aún hoy continúa. Mi intención en este artículo es contribuir a rellenar parte de ese vacío desde mi experiencia dentro de Stop Represión Granada, un colectivo que piensa sobre nuestro contexto de represión actual y actúa contra la represión a la protesta social.

El auge de la represión en el Estado español puede medirse en el endurecimiento de la Reforma del Código Penal y de la Ley Orgánica de Seguridad Ciudadana, comúnmente denominada Ley Mordaza, así como en sus equivalentes locales, las Ordenanzas Cívicas que regulan el uso del espacio público y que comenzaron a sancionar conductas hasta entonces no tipificadas. Otras reformas legislativas como la Ley de Seguridad Privada, la Ley de Enjuiciamiento Criminal o el Pacto antiterrorista son "retorcidamente» empleadas para represaliar el derecho a la protesta. Así, en España al tiempo que contamos con uno de los índices de criminalidad más bajos de Europa, la tasa de población recluida en cárceles es de las más altas². Y en las cárceles se concentran, en un contexto de recortes en servicios públicos como centros de salud mental o de personas sin hogar, un alto porcentaje de población empobrecida y en situación de exclusión social. Como afirman Ávila et al.: "[l]a revolución neoliberal en curso y sus políticas de desigualdad han destilado, entre otras, dos grandes perturbaciones que la incomodan y la amenazan: por un lado, el descontento social y la protesta, y por otro, la exclusión social y la pobreza» (2015: 141).

Della Porta (1999 y 2017) señala que la represión de la protesta tiene una incidencia directa sobre las oportunidades de los movimientos sociales para llevar a cabo sus agendas reivindicativas, además de ser «uno de los mejores y más evidentes indicadores de la actitud institucional ante la protesta» (Della Porta, 1999: 103). Está opinión es compartida y vivida ${ }^{3}$ por Andréj Holm cuando afirma «[q]ue la represión estatal también está ahí para que los movimientos sociales tengan que ocuparse de sí mismos y no de las cuestiones políticas» que les afectan (Sabaté y Holm, 2009: 10).

1 Así denominado por la manifestación fundacional del 15 de mayo de 2011. Fue un movimiento plural y transversal, que partió de la desafección por la política representativa en su toma de decisiones ante la crisis económica (Hughes, 2011). Perugorría y Tejerina señalan la centralidad que adquirieron en el movimiento las "políticas del encuentro" (2013), dándose en el 15M simultáneamente un "proceso cognitivo, emocional y relacional» (2013: 426). Las distintas asambleas se articularon en red y con movimientos de otros países en la denominada «Ola de protesta global» (Antentas, 2015: 10). En el contexto granadino, cuatro de sus grupos de trabajo (Stop Desahucios, Asamblea Feminista Unitaria, Asamblea Interprofesional y Stop Represión) continúan activos.

2 Según el Informe ROSEP (2015) del Observatorio del Entorno Penitenciario, la tasa de encarcelamiento en España está un $32 \%$ por encima de la media europea y en las cárceles españolas hay el doble de presos que en Finlandia o Suecia. La tasa de delito es un $27 \%$ menor que la media europea, ocupando el tercer puesto de países más seguros. El 76\% de las personas reclusas en España lo son por robo.

3 El sociólogo y activista Andrèj Holm ha encarnado distintos episodios de represión, siendo detenido por publicar desde la universidad textos sobre gentrificación que posteriormente fueron utilizados por movimientos que protestaban contra la expulsión de clases populares de barrios históricos, o forzado a dimitir como subsecretario de vivienda en Berlin por haber pertenecido supuestamente a la Stasi (Ministerio para la Seguridad de la RDA). Este mismo hecho fue sancionado por la Universidad de Humboldt de la que se encuentra apartado de investigación y docencia. 
He comenzado planteando un panorama oscuro: el aumento de la represión a la protesta social por parte del Estado español es una forma de ocultar el empobrecimiento de la sociedad y mantener el orden establecido cuando las personas se unen para reivindicar derechos en torno a problemas que les afectan. De este modo, reformas legislativas, ejecutivas y judiciales impulsadas por el Estado fueron creadas ad hoc para la criminalización social o efectiva de quienes protestan. En este sentido, se podría pensar que el Estado tiene cada vez más agencia para actuar, mientras que las personas y colectivos la tienen menos. Pero este no es un artículo pesimista y cómo trataré de mostrar, aunque la represión a la protesta social puede ser vista como un exceso de agencia «que acarrea la subordinación de otros [...] estos otros, nunca están completamente destituidos de agencia, tienen poder y proyectos propios, y la resistencia (de la más sutil a la más evidente) siempre es una posibilidad» (Ortner, 2007b: 76).

El análisis del marco de la represión a la protesta social, aunque interesante y poco documentado, no ocupa un lugar central en este artículo ${ }^{4}$. Mi intención se limita a contextualizar el espacio político en el que Stop Represión Granada lleva a cabo su agenda activista. En este artículo me interesa desarrollar mi experiencia junto al colectivo y especialmente, indagar en el proceso de constitución de Stop Represión Granada como «agenciamiento colectivo" mediante su oposición al poder, pero sobre todo mediante la construcción de pensamiento propio. Para llevarlo a cabo, me apoyo en la etnografía feminista. Desde mi incorporación al colectivo hasta explicitar mi decisión de escribir sobre nosotras mismas transcurrieron tres años, de modo que, más que una observación participante realicé una "participación observada» durante cuatro años (Tedlock, 1991); un proceso de diálogo, análisis y reflexión con mis compañeras. El seminario que relato adoptó la forma de grupo de discusión (Ibáñez, 1979), 4 sesiones de entre 2 y 4 horas con 9 participantes, con importantes matices: conformado y moderado por nosotras mismas, donde mi propia voz aparece en el hilo de las discusiones como una más. También incluyo un ejercicio de análisis y escritura autoetnográfico (Del Valle, 1995; Behar, 1996; Tilley-Lubbs, 2014), lo que me permite pensar en mi condición de investigadora sobre un grupo al que pertenezco y profundizar en la articulación entre vulnerabilidad y agenciamiento como parte del proceso de construcción del colectivo.

Este artículo continúa con la siguiente estructura: en primer lugar, presento nuestro colectivo atendiendo a su surgimiento, organización e identificación/desidentificación, que nos ayudan a entender el agenciamiento colectivo. Para ello parto de la "teoría de la práctica" propuesta por la antropóloga Sherry Ortner (2007a y 2007b). En un segundo y tercer momento presento dos experiencias para mostrar parte de los procesos vividos de agenciamientos colectivos: por un lado de "resistencia» ante la posible existencia de "Listas Negras" y, por otro, de construcción de proyectos propios mediante la organización del "seminario Feminismos». En cuarto lugar, abro un paréntesis para reflexionar desde mi propio lugar situado dentro del grupo en tanto que compañera activista e investigadora académica. A modo de conclusión, propondré un eje de discusión que trata de superar la noción de vulnerabilidad como impotencia, para proponer que es desde la comprensión profunda de nuestra condición vulnerable, que podemos devenir en procesos de agenciamientos colectivos.

4 Para conocer detalladamente los episodios de represión a la protesta social en el contexto del Estado español puede visitarse nuestro blog: http://stoprepresiongranada.wordpress.com. Última consulta: 31/10/2018. 


\section{STOP REPRESIÓN GRANADA.PROCESOS DE AGENCIAMIENTOS}

\section{COLECTIVOS}

Stop Represión nace como grupo de trabajo del 15M granadino, conformado por personas "afectadas» ${ }^{5}$ por sanciones administrativas debido a acciones en el espacio público en las que no sucedieron delitos ni desórdenes y en las que incluso no participaron. En lugar de hacer frente individualmente a los expedientes sancionadores, propusieron entender la represión a la protesta social como un problema común de la sociedad, aunque fueran las personas directamente afectadas quienes la encarnaban.

Si bien en sus inicios era más numeroso, en la actualidad lo conformamos una decena de personas con compromiso estable, mientras otras entran y salen durante los cursos académicos o durante el trabajo con su caso. La mayoría somos mujeres ${ }^{6}$ y la mayoría vivimos en Granada. Por lo demás, hay una disparidad de ocupaciones: asalariadas, desempleadas, autónomas, estudiantes y jubiladas; así como diversidad de trayectorias: iniciamos nuestro activismo a partir del $15 \mathrm{M}$, participábamos en otros movimientos sociales, o perteneciamos a sindicatos del anarquismo social o partidos de izquierda radical.

Al referirme en pasado a nuestras experiencias de lo que el 15M denominó «la vieja política» (Perugorría y Tejerina, 2013: 433), hemos transitado procesos de identificación/des-identificación, al no conformar el colectivo desde un programa político, sino desde un problema común. Trabajando juntas y con otros grupos y personas, nuestros idearios políticos fueron puestos en suspensión, cuestionados y (re)negociados. Como lo explican Fernández-Savater y Rancière:

"Quienes se incluyen pueden hacerlo en tanto que "personas", en tanto que miembros de un grupo de afinidades personales o en tanto que militantes de tal o cual colectivo. Lo esencial es que el «nosotros» pueda estar abierto a cualquiera que lo desee. De hecho, la suspensión de las identidades particulares marca generalmente el comienzo de los movimientos...» (Fernández-Savater y Rancière, 2014: S.p)

Pienso que esta "suspensión de identidades" ha sido importante en tanto que apertura a cualquier "persona», pues "permitió que tanto las personas sin participación política previa como aquellas con diferentes trayectorias militantes se sintieran parte del mismo colectivo" (Perugorría y Tejerina, 2013: 435).

Las actividades que realizamos desde Stop Represión son variadas; sólo citaré algunas que son fundamentales en el proceso de agenciamiento colectivo. Primero, las asambleas, al principio eran semanales y desde hace dos años quincenales; si bien en momentos de mucha actividad (una campaña próxima o el apoyo a un caso) el número de asambleas se multiplica. Segundo, las acciones reivindicativas convocadas por nuestro colectivo o en coordinación con otros grupos: manifestaciones en el espacio público que responden a una

5 Aunque se utiliza la expresión de "víctimas» de la represión, prefiero nombrar a Stop Represión como un colectivo compuesto por afectadas, pues como señala Garcés: «es un desplazamiento que implica un cambio de su propia condición política, al rechazar la pasividad unidireccional, el horizonte de la reparación y transformar en experiencia común lo que antes era visibilidad individual» (2011: 400-401).

6 De ahí el uso del femenino plural para referirme a los/as miembros de nuestro colectivo tal y como hacemos en nuestras asambleas, intervenciones y escritos. 
medida del gobierno o un caso de represión, como cambios legislativos que recortan derechos o sentencias que consideramos injustamente condenatorias. El objetivo de estas acciones es mostrar que la fuerza en la calle es un contrapeso al poder dominante. Tercero, el acompañamiento de casos de represión. Aunque con el descenso de la protesta social desde 2014 hay menos casos, en lo que llevamos de 2018, el grupo acompaña una multa por pegada de carteles (aplicación de la Ordenanza Cívica) y un proceso contencioso-administrativo (aplicación de la Ley Mordaza) por acudir a un desahucio. Aunque la mayoría de los casos son administrativos, otros fueron represaliados bajo el Código Penal, entre ellos el de "Carlos y Carmen», "Titiriteros», o el que afectó a un Centro Social dentro de la "Operación Piñata» ${ }^{\text {? }}$ Contamos con el apoyo de abogados/as que trabajan de forma solidaria, de modo que afrontamos solo los costes de trámites judiciales y pago de multas si se resuelven en contra. El colectivo apoya los casos represivos de personas afectadas a nivel individual y de otros movimientos, como un modo de sortear la afirmación de Holm citada anteriormente de que la represión es una manera de impedir a los movimientos mantener sus agendas por la necesidad de defenderse. Las condiciones de Stop Represión para apoyar un caso son que la persona se implique en las tareas y esté conforme con que haya campaña política: notas de prensa, concentraciones, etc., además del apoyo a su defensa jurídica y costes. Cuarto, hacemos actividades para construir lo que denomino, a la estela de Restrepo (2016) «pensamiento propio»; esto es, la autoformación y difusión de saberes considerados útiles: invitar a una persona experta a dar una charla, participar en una mesa redonda o analizar textos legislativos. Para darle más resonancia a estas actividades, elaboramos documentos que alargan la vida de dichas experiencias. Finalmente, realizamos trabajos antirrepresivos en red, como la vinculación a la red Malla o la campaña por la Amnistía Social ${ }^{8}$. Algunas de estas acciones requieren recursos económicos para lo cual el grupo dispone de una caja de resistencia solidaria y autogestionada.

Esta serie de actividades son impulsadas para resistir al poder dominante, pero más allá de ello, realizamos proyectos propios a través de los que buscamos constituirnos en sujetos colectivos. Por ello, y siguiendo los trabajos de Sherry Ortner (2007a y 2007b), podríamos decir que Stop Represión somos un colectivo con agenciamiento. Ortner profundiza en la capacidad de actuar siempre teniendo en cuenta el contexto. Su concepción de la agencia se desarrolla a partir de una «teoría de la práctica feminista, de minorías, de subalternos, etc." (2007a: 26) a través del análisis de los procesos de agencia que llevan a cabo los

7 Estos son algunos casos en los que hemos trabajado durante nuestras campañas. Carlos y Carmen, fueron condenados a tres años de prisión por el artículo 315 del Código Penal «a los que, actuando en grupo, o individualmente pero de acuerdo con otros, coaccionen a otras personas a iniciar o continuar una huelga». Por el caso titiriteros (Alfonso y Raúl representaban una obra de títeres denunciando la represión al movimiento anarquista) y la Operación Piñata (efectuada en Centros Sociales de Barcelona, Madrid, Palencia y Granada) fueron denunciados por los artículos 576, 577 y 578 del Código Penal por pertenencia o enaltecimiento del terrorismo. En estos dos últimos casos, las personas afectadas estuvieron en prisión preventiva, aunque posteriormente ambas causas fueron archivadas.

8 La Red Malla es un entramado de organizaciones que «monitorean» el impacto de la Ley Mordaza creando una base de datos online donde se registran las sanciones interpuestas, con la finalidad de elevar a organismos internacionales la situación de represión a la libertad de expresión, reunión y protesta. Por su lado, la campaña «Amnistía Social Ya!» aglutina sindicatos, movimientos sociales y asociaciones afectadas por casos de represión exigiendo la derogación de las legislaciones «anti-protesta» con carácter retroactivo, esto es, reembolsando el dinero de las sanciones y aplicando medidas de justicia restaurativa para quienes cumplieron prisión preventiva y luego fueron absueltos o sus casos archivados. Se puede consultar la web de la Red Malla en: https://redmalla.net/\#/map; y la de la campaña Amnistía Social Ya! En: http://www.amnistiasocialya.info/. Última consulta: 06/11/2018. 
grupos que cuestionan la dominación en los contextos que habitan, desvelando sus contradicciones y aportando la esperanza de que el cambio social es posible. Así, la noción de agencia de esta autora se aleja de concepciones que remiten a un actor «autónomo, individualista, occidental», un agente "heroico" que se enfrenta a una entidad, la estructura, insertando la agencia en "tramas de solidaridad [...] en agentes sociales siempre desenvueltos en una multiplicidad de relaciones sociales en la que están enredados y jamás pueden actuar fuera del mismo" (2007b: 46-47). Ortner explica que la aparición de la noción de agencia está relacionada con la emergencia de movimientos sociales a partir de la década de 1980 como una contestación al poder, una agencia de oposición, de resistencia (2007b: 75). Y, además, la autora propone que agencia también tiene que ver con la capacidad de estos grupos para llevar a cabo proyectos "[q]ue nutren deseos de ir más allá de sus propias estructuras de vida, inclusive - y esto es central- de sus propias vidas en estructuras de desigualdad» (2007b: 68).

Aunque Ortner utiliza el concepto de agencia, apuesto por seguir a Guattari y Rolnik (2006) quienes propusieron la noción de agenciamiento colectivo. En su acepción no solo escapan del «individuo heroico", sino que al mismo tiempo se introduce el matiz de no dar al colectivo "una entidad predeterminada» ni concluida, lo que apuntaría al proceso de construcción política «fabricada y modelada en el registro de lo social» (ibídem: 45-46).

Recién constituido, Stop Represión lanzó un manifiesto y convocatoria de manifestación estatal, el 31 de enero de 2012. En dicho manifiesto avanzó que las protestas contra el sistema llevaban aparejadas la represión del propio sistema para su mantenimiento y señalaron la necesidad de visibilización debido al carácter velado de la represión administrativa. En ese comunicado difundieron al resto de asambleas $15 \mathrm{M}$ su propuesta: recurrir las sanciones y agotada la vía administrativa - en la práctica totalidad se resuelven en favor de la propia administración-, presentar recursos contencioso-administrativos lo que conlleva abonar la cuantía de las multas y el pago de costes judiciales ${ }^{9}$. En el mismo comunicado avanzaron la realización de una investigación (recogida de datos, análisis y sistematización) para recoger información sobre estos procedimientos. En concreto indicaban:

«[p]roponemos a cada asamblea la elaboración de un documento acerca de su ciudad donde se recoja la información de todas las multas, explicando el motivo y la cuantía. Al final del documento, reflejar el total de las multas junto a la equivalencia en dinero para mostrar las sumas exageradas que el Estado intenta robar a los que se oponen pacíficamente al orden establecido por los gobiernos. Igualmente se haría en el caso de las detenciones. Nosotras/os no solo vamos a reflejar en nuestro documento la represión al 15M, sino la de otros grupos, colectivos y asambleas de Granada. En la que explicaremos el contexto donde sucedió y las razones que llevó a dichos colectivos a llevar a cabo los diferentes actos.» (VV.AA., 2016: 130)

Como vemos, en Stop Represión se manifiestan dos modos de agenciamiento que, si bien aparecen entrelazados, voy a desagregar para su análisis. Siguiendo a Ortner (2007a y 2007b), nominaré al primero "agenciamiento como resistencia» que implica una oposición al poder

9 Los procedimientos tuvieron que abonar las "tasas Gallardón» —así denominadas por haber sido aprobadas por el Ministro de Justicia Alberto Ruíz Gallardón en noviembre de 2012- que oscilaban entre los 200 y 350 euros para interponer recursos contencioso-administrativos El gobierno derogó esas tasas en febrero de 2015 y el Tribunal Constitucional la declaró nula de pleno derecho en julio de 2016 cuando la mayoría de dichos procedimientos habian sido resueltos. 
dominante; $y$, al segundo, "agenciamiento como proyecto" (investigar, analizar, documentar) centrado en la construcción de "pensamiento propio». El siguiente apartado se dedica al primer modo de agenciamiento - agenciamiento como resistencia - atendiendo específicamente a la lucha contra las posibles "Listas Negras» mientras que el agenciamiento como proyecto es analizado en el apartado subsiguiente mediante el análisis del «seminario Feminismos».

\section{AGENCIAMIENTO COMO RESISTENCIA. LA LUCHA CONTRA LAS POSIBLES «LISTAS NEGRAS»}

Entre 2011 y 2014, el 15M granadino sufrió distintas formas de represión, desde las menos dolosas, ejercidas por la prensa para crear una opinión pública de criminalización ${ }^{10}$, hasta las más duras como cargas policiales y detenciones arbitrarias. Sin embargo, la más recurrente fue la "burorrepresión», entendida como sanciones administrativas, que tanto el gobierno local con el instrumento de la Ordenanza Cívica, como Subdelegación de Gobierno empleando la Ley de Seguridad Ciudadana, interponían a activistas para reprimir la protesta social y su capacidad de resistencia (Oliver, 2013). La "burorrepresión», pese a ser considerada una forma de represión blanda, fue delatada por su capacidad para producir un «efecto desaliento" (De Domingo, 2003); pues, al aplicarse sobre quienes denunciaban la falta de recursos económicos consecuencia de la crisis, disminuía la presencia de activistas que no podian afrontar más gastos. Además, al ser una sanción administrativa, es prácticamente imposible que se elimine tras una reclamación o alegación, ya que es la propia institución quien sanciona y quien responde. Por último, son impuestas por agentes de policía, que tienen reconocido el principio de veracidad, y sin más pruebas que las versiones de las partes, el juez siempre falla a favor de los agentes. Frente a las cargas policiales, que conseguian generar solidaridad entre las personas afectadas, la «burorrepresión» era mucho más efectiva y con menos coste político, por lo que ganaba en centralidad y relevancia; o como resumen Ávila et al.: "los cambios que la "burorrepresion" está sufriendo son de tanta intensidad y envergadura que llegan a poner en tela de juicio otro de sus rasgos más evidentes: su bajo tono punitivo, su carácter infrarrepresivo» (2015: 142).

La primera vez que Stop Represión mencionamos la existencia de "Listas Negras» fue en una nota de prensa del 14 de mayo de 2012. Señalamos que en solo un año, un movimiento pacífico y apoyado por la sociedad había tenido que enfrentar seis detenciones (todas las personas quedaron posteriormente absueltas) y casi 100 multas - cuando el movimiento $15 \mathrm{M}$ se disolviera ascenderían a 164-, acumulando una deuda en multas de más de 52.000 euros (VV.AA., 2016: 183).

Las "Listas Negras» son definidas por nuestro colectivo como archivos policiales extralegales con información de activistas (nombre y apellidos, dirección, DNI), «identificados» visualmente durante acciones no comunicadas (protestas espontáneas, ocupación de bancos o

10 Como ejemplo de criminalización por la prensa, ver: http://www.ideal.es/granada/v/20110607/granada/ilusion-realidad-20110607.html. El higienismo, la participación de menores u ocupación de espacio público son señalados para estigmatizar el movimiento. Última consulta: 05/11/2018. 
instituciones, etc.) y posteriormente sancionados. Las identificaciones visuales (sin que se requiera el DNI) no son ilegales, pues un agente del de policía puede "conocerte de toda la vida». Así, de las 164 sanciones, 110 fueron por identificación visual a 85 personas ¿la policía conocía "de toda la vida» a esas 85 personas? Es poco probable; la mayoría de las personas sancionadas se encontraban en la ciudad realizando sus estudios universitarios, habían cambiado varias veces de domicilio y la dirección en la que recibieron las sanciones no siempre se correspondía con su dirección fiscal. Además, se trató de 164 multas a 85 personas, porque varias de ellas recibieron más de una (algunas más de cuatro) incluso no estando en la ciudad en la fecha en la que se les sanciona, por lo que el grupo de trabajo lanzó la campaña «A mí también me ha multado el Subdelegado de Gobierno» en febrero de 2013, acudiendo a Subdelegación de Gobierno para solicitar expedientes de identificación de cada persona sancionada por identificación visual y conocer qué información estaba disponible en el Cuerpo Nacional de Policía. Los informes PERPOL ${ }^{11}$ de estas personas recogidos meses después fueron negativos; en todos los casos menos uno, indicaban que cada una de estas personas «no era de interés policial», lo que impulsó una campaña de denuncia sobre la posible existencia de "Listas Negras» tal y como afirmó el colectivo en rueda de prensa el 2 de mayo de 2013 (VV.AA., 2016: 238).

Para poder recurrir esas multas, en 63 ocasiones se interpusieron procesos contencioso-administrativos, casos en los que la sanción recibida fue por identificación visual y no por petición de documentación personal in situ. Se ganaron judicialmente 52 casos y se perdieron 11. Los casos resueltos positivamente sentencian que los agentes de policía no pudieron demostrar si la persona estuvo en el acto por el que se les sancionaba, ni de qué la conocían para obtener su dirección y documentación sin solicitarla. Un juzgado incluso dictaminó en varias sentencias que el modo de proceder de los agentes había sido irregular.

El 25 de junio de 2014, cuando la mayoría de los procedimientos contencioso-administrativos habían sido resueltos, Stop Represión presentamos en los juzgados las sentencias ganadas como denuncia, para esclarecer la posible existencia de "Listas Negras». Dos juzgados distintos vieron indicios de delito y admitieron a trámite nuestras denuncias, imputando a cuatro agentes y llamando a declarar a dos más como testigos. En un proceso judicial plagado de obstáculos, de aplazamientos y agentes imputados que pedían declarar tras un biombo como si de testigos protegidos se tratase, el caso fue finalmente archivado en febrero de 2017.

Aunque como colectivo no pudimos esclarecer la existencia de "Listas Negras», el proceso de agenciamiento como resistencia a que la "burorrepresión» no culminara con un "efecto desaliento" que desincentivara a activistas a participar en la protesta social fue exitoso. Mantuvimos durante cuatro años una campaña política, mediática y judicial para que estos hechos no cayeran en el olvido. Compartimos nuestros aprendizajes con otros grupos, y al final, cuando el caso nos fue desfavorable, nosotras ya estábamos trabajando en nuevas formas de agenciamiento, como la construcción de proyectos propios.

11 «Archivos PERsonales de Interés POLicial» es la información que la Policía Nacional recaba sobre cualquier ciudadano/a implicado en un supuesto delictivo, aunque no cuente con antecedentes penales. 


\section{AGENCIAMIENTO COMO PROYECTO. LA CONSTRUCCIÓN DE PENSAMIENTO PROPIO A TRAVÉS DEL SEMINARIO FEMINISMOS}

En este apartado me refiero a la realización de seminarios como vía de construcción de lo que he denominado, siguiendo a Ortner (2007b) «agencia como proyecto». Esta forma de agencia se concreta en la construcción de "pensamiento propio» (Restrepo, 2016), "pensar en nuestros propios términos" y "pensamiento-como-acción», "con una intencionalidad política de intervención y transformación, pero no una sustitución o cancelación del pensamiento por la política» (ibídem: 69-70). En este artículo analizo el seminario Feminismos, pero también llevamos a cabo otro sobre Migraciones. Si bien estos no fueron los primeros espacios de autoformación -en otras ocasiones hemos buscado documentación, leído, analizado y construido pensamiento propio-, su particularidad es la dinámica metodológica y el alcance del mismo.

El seminario Feminismos, surge de varios intereses y acontecimientos que lo desencadenan. Martínez (2017) explica que la agenda feminista en el 15M emerge en un espacio mixto como ocurriera anteriormente en partidos, sindicatos y otros movimientos sociales, pero mientras en estas experiencias el sexismo y el encuentro con otras mujeres activistas «empujaron a algunas mujeres a buscar y crear espacios libres de sexismo, espacios propios, para constituir espacios feministas separados» (ibídem: 79), en el 15M las feministas continúan habitando espacios mixtos, incorporando propuestas y pedagogías, no sin contradicciones (ibídem: 88). Stop Represión es un espacio mixto donde también se incorpora la agenda feminista a su trabajo antirrepresivo. Por un lado, debido al interés individual de algunas miembros del colectivo, por otro, hemos acompañado casos de represión a colectivos feministas ${ }^{12}$, espacios de debate y acciones reivindicativas.

El desencadenante del seminario Feminismos fue la propuesta de una compañera de realizar en 2016 las jornadas «Feminismos Sin Mordazas». En la primera sesión, se presentó el libro Defender a quien defiende (Bondia, Daza y Sánchez, 2015), en el que había escrito un capítulo sobre represión y género. La segunda sesión de las jornadas consistió en una mesa redonda en la que participaron colectivos feministas de distintas ciudades, para compartirnos sus experiencias y tejer redes. Tras las jornadas propusimos a la compañera impulsora la escritura de un texto para difundir la experiencia. Al momento de publicarla emergió un interesante debate sobre si este documento debía incorporarse al resto de trabajos realizados o contar con una sección propia ${ }^{13}$, también percibimos la necesidad de ampliar la mirada colectiva sobre el tema. De este modo, decidimos realizar un seminario que nos permitiera profundizar este debate en el seno del grupo.

El seminario estuvo compuesto por tres sesiones internas y una sesión abierta entre enero y mayo de 2017 dentro del ciclo que llamamos «Tardes a la fresca: Represión desde otras miradas». La primera sesión consistió en construir significaciones propias para el grupo sobre conceptos claves: feminismos, género, dominación, patriarcado, etc. En la segunda, discutimos

12 Como la Asamblea Feminista Unitaria resultante del grupo de trabajo 15M Granada (VV.AA., 2016: 134). Además, hemos colaborado en campañas antirrepresivas de colectivos feministas del estado a quienes invitamos a participar en las jornadas Feminismos Sin Mordaza, como se puede ver en este cortometraje documental https://www.youtube.com/watch?v=JY5MFX_hjUU. Última consulta 06/11/2018.

13 Ver: https://stoprepresiongranada.wordpress.com/2016/12/07/nueva-pestana-del-blog-feminismos-sin-mordazas/. Última consulta: 06/11/2011. 
textos que abordaban dominación y violencia de género, violencia de género y sexual en movimientos sociales, represión desde una perspectiva feminista y el carácter patriarcal del Estado contra las mujeres. La tercera sesión se centró en marcar objetivos y construir un proceso de trabajo a partir de la puesta en común. Y, en la última sesión ya abierta a todo el mundo, contamos con Elena Casado, profesora de sociología de la Universidad Complutense de Madrid, quien generosamente acudió a nuestra invitación para profundizar en nuestros debates.

A continuación, presento tres maneras en las que este seminario llena de contenido lo que denomino, "agenciamiento como proyecto" mediante la construcción de "pensamiento propio»: violencia de género en movimientos sociales; mapa feminista de casos represivos; $y$ concepción del feminismo antirrepresivo.

En primer lugar, en el colectivo hemos pensado las dificultades para afrontar casos de violencia de género al interior de los movimientos sociales. Reconocemos que pese a habitar espacios horizontales y que se presuponen transformadores, existen formas de violencia sexual y de género invisibilizadas. De nuestras lecturas compartidas, debatimos entre otros asuntos, cómo articular una posición antipunitiva ${ }^{14}$ con una lucha contra estas formas de dominación para que no queden impunes. Con respecto a la impunidad en la que se ha mantenido la violencia contra las mujeres en los movimientos sociales, un compañero explicaba ${ }^{15}$ :

"Cuando en 2009 salieron los textos de «las tijeras» ${ }^{16}$ fueron super discutidos y polémicos ${ }^{17}$. En cambio ahora cuando los he estado releyendo para esto, me parecían super sensatos... Recuerdo que en su momento, no es que tomara partido a favor de los maltratadores, pero sí estaba más centrado en que tras la expulsión eran necesarios protocolos para que el agresor pudiera redimirse, pero ahora veo que el cambio en la persona tiene que ser radical para que pueda volver. Lo que con el tiempo me hace ver "tijeras», es que entonces no había protocolo alguno para afrontar estas situaciones y sigue sin haberlo, pero entonces es que se ponía a la víctima a carearse con el maltratador o el violador, que me parece una barbaridad.» (Transcripción del debate, 28 de enero de 2017)

Uno de los problemas para actuar ante un caso de violencia de género en los movimientos es la dificultad para atravesar las dicotomías público/privado o las relaciones de poder que el maltratador puede ostentar dentro del grupo:

«En todos los espacios donde milito, hay muchos tipos de dominaciones, no solo de género, también de clase, racismo, etc. (...). Luego respecto a si es un asunto que debamos trabajar, nos remite a la dicotomía, si es un problema personal, ¿al grupo

14 Entiendo, siguiendo a Segato (2017), el antipunitivismo como un posicionamiento crítico al sistema penal que ante el delito solo contempla el castigo, pero no otras medidas como la restauración de la víctima o la prevención del delito en su base social o en la efectividad de la ley como mecanismo de prevención.

15 En este apartado mi propia voz está presente en simetría con mis compañeras.

16 Se refiere al texto publicado en 2009: Tijeras para todas. Textos sobre violencia de género en los movimientos sociales.

17 Entre 2008 y 2010, se publicaron textos como el anteriormente citado y otros entre los que destaco: Plantemos cara a las agresiones sexistas en los espacios liberados. Guía pedagógica para trabajar en colectivo las agresiones sexistas (2008) o ¿Quién teme a los procesos colectivos? Apuntes críticos sobre la gestión de la violencia de género en los movimientos sociales (2009). Si bien las agresiones sexuales que desencadenaron dichas reflexiones fueron puntuales, muchos espacios negaron un debate profundo argumentando que ya eran por sí mismos horizontales e igualitarios, que no actuarían como policías entre si o que se sobredimensionaban los casos. Esto conllevó que algunos grupos de mujeres abandonaran dichos centros y se autoorganizaran en espacios nomixtos. Un ejemplo de esto último fue el proyecto «La Eskalera Karakola» (González y Araiza, 2016). 
no le compete? Si hay violencia de género, la asamblea puede expulsar, que ha sido ya de por sí una conquista feminista. El problema es que continúa ocurriendo allí donde el agresor no solo domina a su pareja o compañera, sino que tiene otras relaciones de privilegio, como ser valioso para objetivos del grupo, o con mucha trayectoria.» (Transcripción del debate, 28 de enero de 2017)

Otra de las violencias contra las mujeres es la sexual, como puede suceder en entornos lúdicos que también compartimos. Una compañera denuncia que no siempre los grupos mixtos son espacios para trabajar esa cuestión:

\begin{abstract}
"Compartimos muchos espacios, no solo asambleas o grupos de trabajo. Por ejemplo se han dado agresiones sexuales dentro de los movimientos sociales en los espacios festivos. Y que cuando se han denunciado se han minimizado precisamente porque nos conocemos, estamos en un espacio festivo e incluso si fue violación, restarle importancia, como si la violación no fuera la manera en la que tradicionalmente los hombres se apropian del cuerpo de las mujeres como algo que ellas no pueden hacer. Entonces tenemos que defender que a veces los grupos mixtos no funcionan para según qué cuestiones, y no solo con respecto a hombres y mujeres, inclusive feministas y no feministas. Solucionarlo juntos no es simplemente estar juntos en el mismo espacio, sino cómo entendemos el estar juntos.» (Transcripción del debate, 28 de enero de 2017)
\end{abstract}

Posiblemente la mayor complejidad para el colectivo es cómo compaginar la lucha antirrepresiva con la lucha feminista. En este sentido el debate, tal y como nos ayudó a formularlo Elena Casado, transita "entre la impunidad y lo punitivo», entre no ser castigadoras como el patriarcado y no invisibilizar violencias machistas en nuestros movimientos. Una compañera plantea el dilema de la siguiente manera:

«No quiero diluir la responsabilidad del maltratador, pero me preocupa que esas cuestiones no se solucionen guay porque ya contamos con varios ejemplos. Conocemos casos de personas que fueron expulsadas no del colectivo, sino de la ciudad, eso para mi no es justicia tampoco. Usamos la misma forma de castigo contra la que luchamos para impartir justicia por nuestra cuenta... Expulsar de una ciudad me parece mucha violencia sin haber intentado otras fórmulas. (...) Parece que nos resulta super fácil a los movimientos expulsar a alguien y deshacernos del problema en lugar de pensar juntos cómo afrontarlos... y porque más allá de los movimientos sociales, nos los vamos a seguir encontrando por todas partes." (Transcripción del debate, 28 de enero de 2017)

Sin embargo, a falta de nuevas estrategias sobre cómo abordar esta complejidad, la prevención y la protección a quien denuncia ya es en sí mismo un cambio fundamental conforme a lo sucedido hasta ahora. Así una compañera propone:

"Si hay que hacer algo... es mejor comenzar por conocer y analizar cómo funciona la violencia, la dominación y qué hacer para anticiparnos, cómo apoyar a las mujeres. Que hay que rehabilitar al maltratador, pero para mí sería como la última en todo el orden de prioridades. Que no se puede seguir haciendo más hincapié en rehabilitar al maltratador que en ayudar a recuperarse a quien ha sido maltratada, o en evitar que se pueda dar violencia en nuestros espacios. Que las prioridades estén en otro orden.» (Transcripción del debate, 28 de enero de 2017)

En segundo lugar, desde el colectivo hemos reflexionado cómo poner en acción nuestro pensamiento propio. Para ello hemos elaborado una metodología denominada «Mapa de casos 
de represión a colectivos feministas», para sistematizar cómo se reprime de manera concreta a colectivos de mujeres/feministas y, de más amplio alcance, para analizar el carácter patriarcal de la represión. Como la compañera impulsora de este método relata, se trata de:

«Intentar pensar cómo cada episodio represivo reproduce la lógica punitiva patriarcal, incluso si no se dirige a mujeres o a movimientos feministas. De ahí la propuesta de una metodología feminista para mapear casos de represión, que surge de analizar cómo se ha represaliado a movimientos de mujeres pero que puede ser extensible a los otros, que mira la represión como un discurso y práctica del patriarcado.» (Transcripción del debate, 1 de abril de 2017)

Realizamos la construcción del mapa de casos a partir de interrogantes que nos ayudan a analizar el carácter patriarcal de un caso represivo. En concreto, estas preguntas abordan:

- A quién/quiénes se reprime: trayectoria, composición, qué reivindican. Se trata de obtener información sin someter a más investigación de la que afrontan.

-Cuándo se reprime: contexto inmediato y cambios políticos.

-Dónde se produce la represión: espacio público, viviendas, centros sociales, mientras permanecen detenidas.

- Quiénes reprimen: agentes de las instituciones y otros grupos como los sindicatos de la policía o asociaciones vinculadas al catolicismo ${ }^{18}$.

-El tipo de represión: burorrepresión, agresiones, acoso, mediática (construcción de la criminalización).

- El marco legal que se utiliza.

- Reflexionar las consecuencias que tiene para las mujeres y las mujeres madres, entrar en el circuito penal (Juliano, 2009; Restrepo y Francés, 2016).

A partir de este "mapeo" hemos podido situar el auge a la represión al movimiento feminista a partir de 2014 cuando las protestas y movilizaciones aumentan con motivo del proyecto de ley para la "contrarreforma» del derecho al aborto, mostrando que es el derecho a la protesta y no las actuaciones concretas de los grupos activistas, lo que se reprime (García, 2014).

Por último, desde el colectivo estamos avanzando en un posicionamiento teórico-político que hemos llamado: Feminismo antirrepresivo ${ }^{19}$. Este posicionamiento reconoce, por un lado, que la lucha contra "[I]os mecanismos violentos de la represión debe comprometerse con la deconstrucción de los discursos, ideologías y metáforas de género que están en la base, tanto de la construcción de las instancias de violencia -industria militar, Estado, familia heteronormativa, leyes autoritarias, mercado de trabajo capitalista- como de subjetividades violentas» (Mato, 2015: 69); y, por otro lado, denuncia la instrumentalización de

18 La Asociación Española de Abogados Cristianos o la organización Hazte.Oír, por ejemplo, están detrás de las denuncias de casos de represión a colectivos feministas y LGBTQI como la "procesión del coño insumiso" o la ocupación de la capilla de la Universidad Complutense de Madrid.

19 Una primera publicación sobre nuestros avances se puede leer aquí: «¿Por qué el feminismo es fundamental para la lucha antirrepresiva?», Píkara Magazine, 07/03/2018, http://www.pikaramagazine.com/2018/03/porque-el-feminismo-es-fundamental-para-la-lucha-antirrepresiva/. Última consulta: 10/11/2018. 
las reivindicaciones feministas para ampliar el poder punitivo, sabiendo que el derecho penal está para castigar a quien comete delitos y no para proteger a las víctimas (Restrepo y Francés, 2016) ${ }^{20}$. Una compañera lo planteaba en la última sesión interna de nuestro seminario:

"Cómo pensar en defender a las mujeres y protestar contra el patriarcado sin dar una respuesta punitiva que también es patriarcal. Como por ejemplo lo que está sucediendo con el «delito de odio» o el de "ofensa al sentimiento religioso». Que se supone que es una reivindicación de las minorías pero que son esos propios grupos los que son represaliados a partir de esos artículos penales. Entonces habría que comenzar por desmontar el carácter patriarcal y represor que se blanquea a través de los grupos a los que supuestamente se protege.» (Transcripción del debate, 1 de abril de 2017)

Otra compañera refuerza este planteamiento:

«Como grupo feminista antirrepresión no contamos con respuestas alternativas al castigo patriarcal, pero tampoco queremos utilizar el sistema patriarcal para otras formas de violencia contra las mujeres, pero lo que sí podemos hacer es mostrar que la represión del Estado es patriarcal y cómo afecta a las mujeres y movimientos de mujeres.» (Transcripción del debate, 1 de abril de 2017)

A través del análisis de las tres líneas dentro del «Seminario Feminismos», he tratado de argumentar como Stop Represión muestra una «agenciamiento como proyecto» (Ortner, 2007b), concretizado en la construcción de "pensamiento propio». Ello se sostiene en el análisis y la reflexión sobre dinámicas micropolíticas como la violencia de género en los movimientos sociales, elaborando una metodología feminista para sistematizar casos represivos y construyendo lo que hemos comenzado a llamar "Feminismo Antirrepresivo" que deviene en nuevos interrogantes, pero que avanza en una propuesta que identifica al grupo para actuar de una manera propia ante su lucha política.

\section{UN EJERCICIO DE AUTOETNOGRAFÍA VULNERABLE. DES-IDENTIFICAR LA AGENCIA INDIVIDUAL PARA PARTICIPAR DE AGENCIAMIENTOS COLECTIVOS}

Hasta llegar a conceptualizar el grupo al que pertenezco como un proceso de agenciamiento colectivo anduve un camino inverso en el que reflexioné sobre cómo mi experiencia junto a ellas había transformado mi práctica investigadora ${ }^{21}$. Para ello tuve que observarme a mí misma en el proceso, des-autorizándome y des-identificándome como la persona que analiza y escribe textos, habla en público o ejerce la portavocía y admitiendo que, aunque investigadora, en el colectivo solo era una compañera más, que des-aprendía dentro del pro-

20 Un ejemplo reciente ha sido el debate sobre la ampliación de la prisión permanente revisable en casos de delitos de violencia sexual, feminicidios e infanticidios.

21 Aunque se trate de un ejercicio autoetnográfico, me vengo preocupando por la cuestión de cómo articular militancia e investigación desde hace algún tiempo (Sebastiani y Cota, 2015). 
ceso compartido, horizontal y cotidiano. En definitiva, tuve que aprender a desnudarme de mi agencia individual y encaminarme hacia un agenciamiento colectivo que "[n]o solo acaba con el conocido papel del intelectual, sino también con los mecanismos de legitimación de su palabra y de sus canales de expresión ¿Desde dónde se piensa hoy? ¿Quién puede hacerlo?» (Garcés, 2011: 396).

Mi incorporación tuvo lugar durante el desarrollo del caso de Carlos y Carmen. Antes había acudido a algunas de sus acciones y mantenía relaciones con algunas de sus miembros. El desencadenante fue la petición de entregarles un vídeo que había realizado durante la Huelga del 29 de marzo ${ }^{22}$ y me animé a involucrarme. Cuando tres años después, nuestro grupo comenzó a reflexionar sobre y desde el feminismo, nuestra experiencia me pareció un eje central en mi investigación centrada en la etnografía feminista. Ello porque nuestras nuevas inquietudes desbordaban lo que habia constituido la autoformación, centrada en dar respuesta a las actuaciones represivas, y comenzaban a orientarse hacia un proyecto propio de construcción de conocimiento. Pero al mismo tiempo me pareció problemático plantearles la cuestión, pues consideraba que mi des-autorización como parte de nuestro agenciamiento colectivo, contradiría el hecho de estar reflexionando sobre mi propia experiencia y la del grupo (Anderson, 2006: 380). Transcurrió algún tiempo hasta que pude verbalizar mi deseo de simultanear mi pertenencia como activista-compañera e investigadora-compañera y formular una propuesta acerca de mi interés teórico y metodológico: «¿Desde dónde se piensa hoy?», se trataba de visibilizar y explicar cómo Stop Represión construye conocimiento, $y$, «¿Quién puede hacerlo?», centrándome en las implicaciones que ha tenido sobre mi práctica de investigación la experiencia compartida (Cox, 2014).

Al formar parte del propio grupo sobre el que investigo e incorporar nuestras vivencias "en lo que nos han enseñado a pensar como el análisis de hechos sociales impersonales» (Behar, 1996: 12) y "obtener el 'punto de vista nativo', pero por favor sin realmente 'volverse nativo'» (ibídem: 9), pensé en la escritura autoetnográfica como recurso que me permitiría relatar desde mí misma, aquellos análisis y reflexiones que como compañera-investigadora realizaría de nuestra experiencia, cuidando de no re-apropiar y distinguir los saberes elaborados surgidos en colectivo (Esteban, 2017). Pues con la escritura autoetnográfica:

«me puedo posicionar en la investigación para examinar críticamente mis propias prácticas como investigadora, navegando los espacios vulnerables que requieren un examen de mis propias palabras y acciones con el mismo cuidado que me dirige cuando examino las de las y los otros participantes en el estudio. Mi vulnerabilidad también me causa ser más consciente de la vulnerabilidad de las otras personas..." (Tilley-Lubbs, 2014: 279)

En este apartado, voy a referirme a la vulnerabilidad como una noción ambivalente pues, por un lado, «señala las grietas de nuestra incompetencia (...). Pero, por otro lado, la vulnerabilidad es también nuestro vínculo fundamental con los otros, lo que enlaza nuestra existencia a otras existencias» (Garcés, 2011: 402). Comenzaré por trazar simetrías entre lo que vengo pensando como investigadora a partir de lo vivido y lo encontrado en el análisis del proceso grupal. El origen de nuestro colectivo partió de considerar que la «burorrepresión» -las sancio-

22 Elaboré el vídeo de la Huelga del 29M como parte de una inquietud por mostrar el ambiente plural, festivo y relacional que atravesó el acontecimiento desde la perspectiva del 15M. El vídeo puede visionarse aquí: www. youtube.com/watch?v=Q-PA-F5V6d0. Última consulta: 09/11/2018. 
nes administrativas que les convirtieron en afectadas - se aplica sobre individuos que tienen que defenderse por sí mismos, pero esa agencia individual es tan precaria que conlleva impotencia y "efecto desaliento»: incapacidad de actuar, disminución del número de personas que protestan. Escribe Gil a propósito de la «ontología de la precariedad» de Butler (2010):

\begin{abstract}
"[l]a potencia aparece en el momento en el que el individuo no niega, sino que se hace cargo del estado de precariedad que lo atraviesa. (...). La potencia política aparece cuando se pregunta cómo queremos vivir juntas y juntos, partiendo de la certeza de habitar un mundo común desde la diferencia. En otras palabras, la potencia aparece cuando pregunto: ¿cómo hacer de la vulnerabilidad, con sus dificultades y límites, una fortaleza?» (Gil, 2014: 190)
\end{abstract}

No negar nuestra vulnerabilidad posibilitó pensar y actuar desde un agenciamiento colectivo, del mismo modo que aceptar mi vulnerabilidad como investigadora posibilitó la construcción de una experiencia de investigación junto al colectivo, como sucedió durante el seminario de feminismos. En esta noción de vulnerabilidad profundiza Esteban (2015), quien retoma el concepto de "crisis de la presencia» de De Martino (1999) y actualizado por Fernández-Savater (2011, apud Esteban, 2015). Según este concepto, el sujeto (académico/político) entra en crisis en su concepción "auto-suficiente» con "voluntad propia» y agencia, y en lugar de aferrarse a la incertidumbre, "reclama una idea de la política basada en el "estar-juntxs", "hacer-cosasjuntxs"» (ibídem: 85). Las nociones de vulnerabilidad y crisis de la presencia contribuyen a la desestabilización de «nuestras identidades y convicciones políticas pero, al mismo tiempo, posibilitan la apertura al mundo y la constatación y redefinición de la relacionalidad, de lo común» (ibídem: 86). De modo que asumir la vulnerabilidad no era solo una cuestión central en el origen de nuestro proceso de agenciamiento colectivo, sino que "estar juntxs» y "hacer-cosas-juntxs" me obligaba a repensar los límites de mi investigación y mi propia capacidad para dar cuenta de los procesos tejidos en colectivo. Al comienzo me pareció incompatible la escritura individual de un artículo sobre un colectivo al que pertenezco. En una ocasión, tras escribir dos compañeras un informe sobre género y represión ${ }^{23}$ fruto de una indagación colectiv,a tuvimos que decidir cómo firmarlo: ¿cómo grupo? ¿las dos personas? La propuesta de otra compañera fue que el grupo salía reforzado con los nombres de las autoras y el del colectivo pues; dos nombres conocidos más allá de los movimientos sociales podian ampliar las audiencias y eso beneficiaría a todo el grupo. Es decir, no se trataba de renunciar per sé a la autoría individual sino decidir juntas, «quién(es)» firmamos cada trabajo, teniendo en cuenta "para qué» está escrito. Pero la escritura individual de una experiencia colectiva puede no responder a las expectativas de quienes hemos participado en la construcción de esos saberes y experiencias (Behar, 1996: 24); al fin y al cabo, la transcendencia de mi investigación puede alcanzar menos audiencia, que los escritos en colectivo para la acción política.

Como activista en proceso de agenciamiento colectivo, como investigadora que necesita del colectivo para "pensar juntxs» y como compañera entrelazada al grupo por los afectos y relaciones (Gregorio, 2006), hacer de mis compañeras sujetos vulnerables a la mirada voyeur de la investigadora en la que me convierto (Wolf, 1996; Abu-Lughod, 2012), conlleva que yo misma exponga mi vulnerabilidad, asumiendo que «la antropología no es para los de corazón blando" (Behar, 1996: 22).

23 El informe (Palomares, Mato y Cota, 2017) se puede consultar aquí: http://iridia.cat/wp-content/uploads/ repressio_genere-2.pdf. Última consulta: 06/11/2018. 


\section{EJES PARA LA DISCUSIÓN}

Como investigadora-activista-compañera en Stop Represión Granada, he tratado en este artículo de mostrar un proceso de agenciamiento colectivo de resistencia durante la lucha por el esclarecimiento de posibles "Listas Negras" y el desarrollo de un proyecto propio, el Seminario Feminismos, que ha dado lugar a la construcción de textos, encuentros y acciones políticas para un posicionamiento feminista antirrepresivo y un ahondamiento en nuestra propia práctica política. Aunque en este artículo he separado las dos formas de agenciamiento colectivo, quisiera regresar a Ortner cuando afirma:

«Tal vez la resistencia siempre sea de esta naturaleza: proteger un proyecto o el derecho a tener proyectos. Pero una vez resalto la distinción entre agencia de poder y agencia de proyectos, ésta es en gran medida, heurística. En la práctica, los dos modos acostumbran a ser inseparables.» (2007b: 68)

Mientras que los procesos de agenciamiento, como resistencia y como proyecto, fueron saberes aprendidos, adquiridos y construidos en colectivo, la reflexión a pensar nuestro colectivo como un conformado por sujetos vulnerables vino tras un proceso de análisis y reflexión personal para el que tuve que exponerme simultáneamente como activistacompañera e investigadora-compañera; esto me situó en un lugar vulnerable, pero ¿no es acaso nuestro colectivo uno conformado por la ambivalencia de la vulnerabilidad: la impotencia de asumir individualmente una agencia frente al poder que reprime y emprender procesos de agenciamiento colectivo desde "nuestro vínculo fundamental con los otros?" (Garcés, 2011: 402).

Vulnerabilidad y agencia no solo no son incompatibles, sino que se encuentran entremezcladas en los procesos de agenciamiento colectivo. La resistencia a la cada vez más creciente represión, a su sofisticación y diversificación, a su «efecto desaliento» (De Domingo, 2003) así como la posibilidad de ahondar en una contribución propia al feminismo desde nuestro lugar antirrepresivo posicionado pasó por asumir nuestra "crisis de la presencia» (Esteban, 2015). Crisis de la presencia desde la que sumarnos a otros sujetos todos ellos vulnerables, no tratando de superar dichas vulnerabilidades, sino asumiéndolas en su plenitud, como un modo de "pensar juntas" y "hacer cosas juntas», deviniendo de este modo en "agenciamientos colectivos» que siempre encuentran intersticios desde los que resistimos al poder dominante y creamos nuestros proyectos propios.

\section{BIBLIOGRAFÍA}

Abu-Lughod, L. (2012). Escribir contra la cultura. Andamios. Revista de Investigación Social, 9(19), 129-157.

Anderson, L. (2006). Analytic autoethnography. Journal of Contemporary Ethnography, 35, 373395.

Antentas, J.M. (2015). Internationalist Challenges: Antiglobalisation, Occupy, and Indignados. Globalizations, 13, 469-483. 
Ávila, D., et al. (2015). La burorrepresión de la protesta y de la pobreza. En D. Bondia (Dir.), Defender a quien defiende. Leyes mordaza y criminalización de la protesta en el estado español (pp. 141-168). Barcelona: Icaria.

Behar, R. (1996). The vulnerable observer: anthropology that breaks your heart. Boston: Beacon press.

Bondía, D. (Dir.), Daza, F., y Sánchez, A. (Coords.) (2015). Defender a quien defiende. Leyes mordaza y criminalización de la protesta en el Estado español. Barcelona: Icaria.

Cota, A., García, E., y Rodríguez, J. (2013). ¿Por qué no nos dejan hacer en la calle Prácticas de control social y privatización de los espacios en la ciudad capitalista. Granada: COTALI y Grupo de Estudios Antropológicos La Corrala.

Cox, L. (2014). Movements Making Knowledge: A New Wave of Inspiration for Sociology? Sociology, 48, 954-971.

De Domingo, T. (2003). La argumentación jurídica en el ámbito de los derechos fundamentales: en torno al denominado «chilling effect» o "efecto desaliento». Revista de Estudios Políticos, 122, 141-166.

Del Valle, T. (1995). Metodología para la elaboración de la autobiografía. En C. Sanz (Coord.), Invisibilidad y presencia, Actas del Seminario Internacional "Género y trayectoria profesional del profesorado universitario (pp. 279-289). Madrid: Instituto de investigaciones feministas.

Della Porta, D. (1999). Movimientos Sociales y Estado: algunas ideas en torno a la represión policial de la protesta. En D. McAdam, J. McCarthy y M. Zald (Eds.), Movimientos sociales: perspectivas comparadas (pp. 100-142). Madrid: Istmo.

Della Porta D., y Norman, A. (05/12/2017). Entrevista a Donatella della Porta: la creciente criminalización de la protesta. Open Democracy. https://www.opendemocracy.net/ democraciaabierta/donatella-della-porta/entrevista-donatella-della-porta-lacreciente-criminalizaci-

Esteban, M.L. (2015). La reformulación de la política, el activismo y la etnografía. Esbozo de una antropología somática y vulnerable. ANKULEGI, 19, 75-93.

Esteban, M.L. (2017). Investigadora, profesora, activista y testigo de los cambios en el País Vasco: reflexiones en torno a la gestión de identidades y participaciones múltiples. XIV Congreso de Antropología de la FAAEE: Antropologías en transformación: sentidos, compromisos y utopías, Valencia.

Fernández-Savater, A., y Rancière, J. (24 de enero de 2014). Potencias y problemas de una política del 99\%: entrevista con Jacques Rancière. Interferencias. Eldiario.es.

Garcés, M. (2011). ¿Qué podemos hacer? O sobre las intimidades de la crítica. En O. Cornago (Ed.), A veces me pregunto por qué sigo bailando (pp. 393-408). Madrid: Contintametienes.

García, J. (2015). Feminismos en tiempos de resistencias a la austeridad y confluencias por la ruptura con el 78. Anuario de Movimientos Sociales 2014. Bilbao: Fundación Betiko.

Gil, S. (2014). Ontología de la precariedad en Judith Butler. Repensar la vida en común, ÉNDOXA: Series Filosóficas, 34, 287-302. 
González, R., y Araiza, A. (2016). Feminismo y okupación en España. El caso de la Eskarela Karakola, Sociológica, 87, 207-236.

Gregorio, C. (2006). Contribuciones feministas a problemas epistemológicos de la disciplina antropológica, AIBR, 1(1), 22-39.

Guattari, F., y Rolnik S. (2006). Micropolítica. Cartografias del deseo. Madrid: Traficantes de sueños.

Hughes, N. (2011). 'Young People Took to the Streets and all of a Sudden all of the Political Parties Got Old'. Social Movement Studies, 10(4), 407-413.

Ibáñez, J. (1979). Más allá de la sociología. Madrid: Siglo XXI.

Juliano, D. (2009). Estrategias femeninas de supervivencia y estereotipos. Mesa redonda: Nosotras, las malas mujeres. Debates feministas sobre la prostitución. Jornadas Feministas Estatales. Granada 30 años después: aquí y ahora (pp. 615-625), Federación de Organizaciones Feministas del Estado español: autoeditado. Disponible en http://www. feministas.org/nosotras-las-malas-mujeres-debates.html

Martínez, M. (2017). «La revolución será feminista, o no será»: Reflections on feminisms and the 15M. En B. Tejerina e I. Perugorría (Eds.), Crisis and social mobilization in contemporary Spain (pp. 73-94). Crisis and Social Mobilization in Contemporary Spain. The 15M Movement. New York: Routledge.

Mato, M. (2015). Apuntes para pensar el género como elemento constitutivo de la represión. En D. Bondía (Dir.), Defender a quien defiende. Leyes mordaza y criminalización de la protesta en el estado español (pp. 67-106). Barcelona: Icaria.

Oliver, P. (Coord.) (2013). Burorrepresión. Sanción administrativa y control social. Albacete: Editorial Bomarzo.

Ortner, S. (2007a). Uma atualizaçao da teoría da práctica. En VV.AA., Conferências ediálogos: saberes e prácticas (pp. 19-44). Brasília: Blumenau.

Ortner, S. (2007b). Poder e projetos: reflexoes sobre agència. En VV.AA., Conferências e diálogos: saberes e prácticas (pp. 45-80). Brasília: Blumenau.

Palomares, M. (Calala-Fondo de Mujeres), Mato, M., y Cota, A. (Stop Represión Granada). (2017). Repressió, gènere i feminismes. En T. Bonilla (Coord.), Informe Repressió i Gènere. Resistències i aportacions a la lluita anti repressiva des dels feminismes (pp. 63-88). Barcelona: Defender a quien defiende.

Perugorría, I., y Tejerina, B. (2013). Politics of the encounter: Cognition, emotions, and networks in the Spanish 15M. Current Sociology, 61(4), 424-442.

Red de Organizaciones Sociales del Entorno Penitenciario (ROSEP). (2015). Estudio de la realidad penal y penitenciaria: una visión desde las entidades sociales. https:// plataformarosep.files.wordpress.com/2016/04/estudio-de-la-realidad-penal-ypenitenciaria-una-visic3b3n-desde-las-entidades-sociales.pdf.

Restrepo, E. (2016). Descentrando a Europa: aportes de la teoría postcolonial y el giro decolonial al conocimiento situado. Revista Latina de Sociología, 6, 60-71. 
Restrepo, D., y Francés, P. (2016). Rasgos comunes entre el poder punitivo y el poder patriarcal. Revista Colombiana de Sociología, 39, 21-46.

Sabaté, l., y Holm, A. (2009). Conversando con Andrej Holm. Por unas ciencias sociales críticas con las transformaciones urbanas. Contextos. Revista d'Antropologia i Investigació Social, 3, 5-18.

Sebastini, L., y Cota, A. (2015) "Que no, que no, que no nos representan», o repensando la relación entre investigación y activismo a partir de nuestras experiencias vividas. ANKULEGI, 19, 43-58.

Segato, L. (2017). Feminicidio y los límites de la formación jurídica. Página 12, 1-6. 26/05/2017.

Tedlock, B. (1991). From participant observation to the observation of participation: the emergence of narrative ethnography, Journal of Anthropology Research, 47(1): 69-94.

Tilley-Lubbs, G.A. (2014). Critical Authoethnography and the Vulnerable Self as Researcher, Multidisciplinary Journal of Educational Research, 4: 268-285.

VV.AA. (2016). Archivo 15M Granada. Granada: Stop Desahucios y Stop Represión Granada.

Wolf, M. (1992). A thrice-told tale. Feminism, postmodernism and ethnographic responsibility. Stanford: University Press. 